\title{
CORRIGENDUM
}

\section{Microbial ecology of the equine hindgut during oligofructose-induced laminitis}

Gabriel J Milinovich, Paul C Burrell, Christopher C Pollitt, Athol V Klieve, Linda L Blackall, Diane Ouwerkerk, Erika Woodland and Darren J Trott

The ISME Journal (2008) 2, 1169; doi:10.1038/ismej.2008.100

Correction to: The ISMEJ Journal (2008) 2, 1089-1100; doi:10.1038/ismej.2008.67

The authors of the above noted an error in the publication of this paper (AOP and in this issue) in

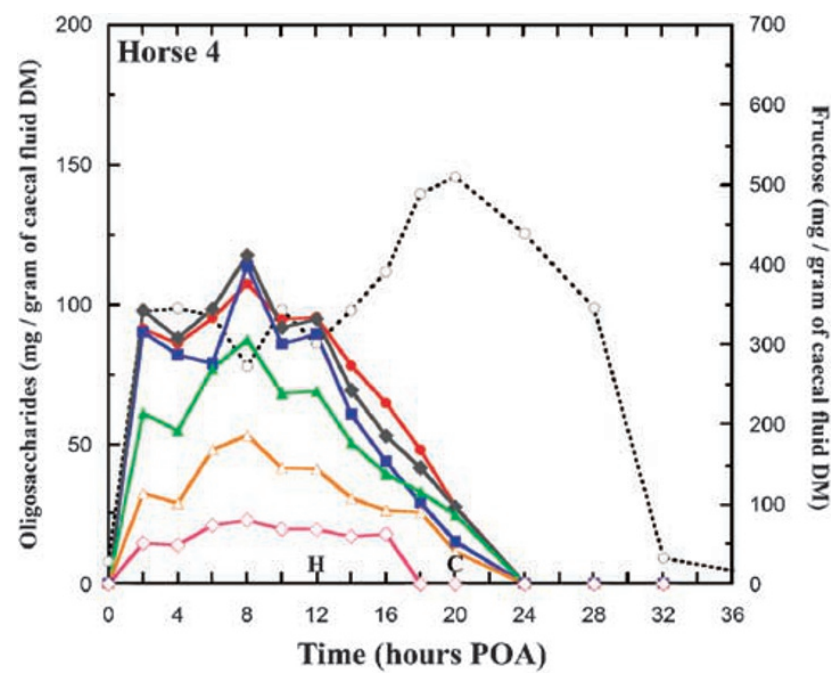

the $y$ axis to Figure 3. The right hand $y$ axis title for horse 4 should read: 'Fructose (mg/gram of caecal fluid DM).' The corrected figure for horse 4 is shown below. 